\title{
ANALISIS STRATEGI PEMASARAN PADA PT. PRAMBANAN KENCANA
}

\author{
Willianto \\ Program Studi Magister Manajemen Universitas Tarumanagara \\ willianto.bow@gmail.com
}

Masuk : 30-11-2019, revisi : 06-01-2020 diterima untuk diterbitkan : 07-01-2020

\begin{abstract}
PT. Prambanan Kencana is an importer and distribution company which is founded in 1953 dan they offer quality food and beverages product. This research aims to analyze marketing strategy being used in PT. Prambanan Kencana in accordance to the internal and external factor and to seek for alternative marketing strategy in PT. Prambanan Kencana by utilizing Matriks IFE, Matriks EFE, Matriks IE, and Matriks SWOT. Method used is qualitative descriptive. The result of the research depict that PT. Prambanan Kencana has its own strength, weakness, opportunity and Threats and there are strategies to handle it. PT. Prambanan Kencana also is on the V grid in Matriks IE in which the best strategy is the hold and maintain strategy.
\end{abstract}

Keywords : IFE, EFE, SWOT, IE,, marketing, PT. Prambanan Kencana, distribution

Abstrak : PT. Prambanan kencana adalah sebuah perusahaan importir dan distribusi yang berdiri sejak tahun 1953 dan menawarkan produk-produk makanan dan minuman impor dengan kualitas yang baik. Penelitian ini bertujuan untuk menganalisis strategi pemasaran yang digunakan di PT. Prambanan Kencana terkait dengan faktor internal dan eksternal dan menelaah alternatif strategi pemasaran dengan menggunakan beberapa alat bantu yaitu matriks IFE, matriks EFE, Matriks IE, dan matriks SWOT. Metode yang digunakan adalah metode kualitatif deskriptif. Hasil dari penelitian menggambarkan bahwa PT. Prambanan Kencana memiliki kekuatan, kelemahan, peluang dan ancaman dan ada strategi untuk mengatasinya. PT Prambanan Kencana juga berada di posisi V di matriks IE dimana strategi terbaik adalah untuk menjaga yang sudah ada.

Kata Kunci : IFE, EFE, SWOT, IE, pemasaran, PT. Prambanan Kencana, distribusi

\section{PENDAHULUAN}

Industri makanan dan minuman di Indonesia tumbuh sangat pesat beberapa tahun belakangan dan naik tahun per tahun dengan contoh di tahun 2017, pertumbuhannya mencapai 9.23\% atau naik dari 2016 yang sebesar 8,46\% (yasmin 2017). Hal ini membuat banyak sekali perusahaan yang ingin terjun ke dalam industri makanan dan minuman di Indonesia dan menimbulkan persaingan yang cukup ketat terhadap pemain lama di industry ini.

PT. PRAMBANAN KENCANA merupakan sebuah perusahaan importir dan distribusi untuk produk-produk bahan baku kue. Namun dengan pesatnya perubahan jaman dan banyaknya ancaman dari kompetitor baru membuat PT. PRAMBANAN KENCANA harus memikirkan ulang mengenai strategi pemasaran yang harus diterapkan ke depannya.

Oleh sebab itu, melihat pentingnya analisa strategi pemasaran terhadap perusahaan, penelitian ini bermaksud untuk menganalisis strategi pemasaran yang digunakan di PT. Prambanan Kencana terkait dengan faktor internal dan eksternal dan menelaah alternatif strategi pemasaran yang bisa digunakan untuk meningkatkan kinerja perusahaan. 


\section{TELAAH KEPUSTAKAAN \\ Pemasaran \\ Definisi Pemasaran}

Pemasaran adalah suatu proses perencanaan dan eksekusi, mulai dari tahap konsepsi, penetapan harga, promosi, hingga distribusi barang-barang, ide-ide dan jasa, untuk melakukan pertukaran yang memuaskan individu dan lembaga-lembaganya (Kasali, 1998)

\section{Strategi Pemasaran}

Strategi pemasaran sebagai kegiatan menyeleksi dan penjelasan satu atau beberapa target pasar dan mengembangkan serta memelihara suatu bauran pemasaran yang akan menghasilkan kepuasan bersama dengan pasar yang dituju. (Lamb, Hair, \& McDaniel, 2001)

\section{Internet Marketing}

\section{Pengertian Pemasaran Online}

Pemasaran online Proses memasarkan produk dan layanan kepada pelanggan dengan menggunakan media web. Promosi, Iklan, Transaksi dan pembayaran dapat dilakukan melalui halaman web. (Ling, 2006)

\section{Pengaruh Pemasaran Online}

Pemasaran online menciptakan perubahan prilaku yang mendasar dalam bisnis dan konsumen serupa dengan yang terkait dengan pengenalan mobil dan telepon yang mengurangi kebutuhan untuk pendekatan channel (Jagdish N. S. \& Sharma. A., 2005)

\section{Bauran Pemasaran}

Bauran Pemasaran adalah sekelompok alat pemasaran yang dibaurkan oleh perusahaan untuk memberikan hasil yang diinginkannya di target pasar. Bauran pemasaran ini dikelompokkan menjadi tujuh kelompok variabel yang disebut "7 P": Product (Produk), Price (Harga), Place (Tempat) \& Promotion (Promosi), People (orang), Process (Proses), Physical Evidence (Bukti fisik) (Kotler \& Armstrong, Prinsip-Prinsip Pemasaran Jilid 1, 2008).

\section{Analisis Lingkungan Eksternal dan Internal \\ Analisis Lingkungan Eksternal}

Analisis lingkungan eksternal perlu dilakukan agar perusahaan mengetahui peluang dan ancaman yang berasal dari luar lingkungan perusahaan. (David, 2011)

\section{Analisis Lingkungan Internal}

Analisis lingkungan internal perlu dilakukan agar perusahaan mengetahui kekuatan dan kelemahan yang berasal dari dalam lingkungan perusahaan. (David, 2011)

\section{Analisis dan Pemilihan Strategi Tahap Masukan \\ EFE Matriks (David, 2011, p.80)}

EFE Matriks merupakan sebuah strategi untuk merangkum dan mengevaluasi faktorfaktor eksternal perusahaan. Tujuannya adalah untuk memvisualisasikan penilaian kondisi bisnis saat ini.

\section{IFE Matriks (David, 2011, p.122)}

IFE Matriks merupakan sebuah strategi untuk merangkum dan mengevaluasi faktorfaktor internal perusahaan. Tujuannya adalah untuk melihat kuat atau lemahnya kondisi internal perusahaan. 


\section{Tahap Penyesuaian \\ SWOT Matriks}

Analisis SWOT menggunakan alat yang disebut Matriks SWOT untuk mengaudit atau menilai sebuah organisasi beserta lingkungannya.

\section{IE Matriks}

IE Matriks memiliki sembilan kuadran di mana masing-masing kuadran menunjukkan strategi apa yang tepat untuk diimplementasikan.

\section{GAMBARAN UMUM PERUSAHAAN}

PT. Prambanan Kencana adalah sebuah perusahaan yang bergerak di bidang distribusi makanan, lebih tepatnya bahan baku kue dan beberapa bahan makanan lainnya. Didirikan pada tahun 1953, pada awalnya PT. Prambanan Kencana masih berbentuk CV dan baru di tahun 1975 PT. Prambanan Kencana merubah status badan hukum menjadi PT. dan mulai agresif mengembangkan bisnisnya.

\section{METODOLOGI PENELITIAN \\ Penelitian Kualitatif}

Dalam penelitian kualitatif, penulis bertolak dari data, memanfaatkan teori yang ada sebagai bahan penjelas, dan berakhir dengan suatu gagasan.

\section{Teknik Pengumpulan Data Wawancara}

Penulis memperoleh data dengan wawancara langsung kepada karyawan PT Prambanan Kencana dari beberapa departemen.

\section{Observasi}

Penulis adalah karyawan aktif di perusahaan, sehingga dapat melihat dan merasakan secara langsung dinamika kegiatan perusahaan.

\section{ANALISIS DAN PEMBAHASAN Analisis EFE \& IFE Matriks EFE Matriks}

Ditemukan bahwa peluang yang memiliki skor paling besari di 0.404 adalah dari sisi produk yaitu banyak potensi produk yang bisa diimpor. Ditemukan juga faktor "kompetitor memiliki cabang di lebih banyak kota" menjadi ancaman yang paling besar dengan skor 0,082

\section{IFE Matriks}

Semua kekuatan yang telah dianalisis, ditemukan bahwa Produk dengan skor 0.300 adalah faktor yang dianggap paling penting dan merupakan kekuatan utama dari Perusahaan. Selain itu, dalam analisis kelemahan, faktor yang menjadi kelemahan utama adalah tenaga penjual yang belum terlalu menguasai produk secara detail

\section{Analisis Matriks IE}

Hasil total skor dari IFE menunjukan skor 2.550 yang menunjukan bahwa posisi perusahaan ada di posisi sedang. Sedangkan hasil skor EFE senilai 2.327 juga menunjukan bahwa posisi perusahaan juga posisi sedang dalam menghadapi peluang dan ancaman dari luar.

Hasil persilangan dari IFE dan EFE menunjukan PT. Prambanan berada di kuadran V. Adapun strategi yang cocok diterapkan untuk di kuadran $\mathrm{V}$ ini adalah strategi Hold and Maintain Strategy, 


\section{Matriks SWOT}

Analisis faktor internal dan eksternal perusahaan, maka dapat disusun beberapa alternatif strategi berdasarkan analisis matrik SWOT. Hasil dari analisis matrik SWOT pada bauran pemasaran PT. Prambanan kencana dapat dilihat pada di bawah ini.

\begin{tabular}{|l|l|}
\hline \multicolumn{1}{|c|}{ Kekuatan } & \multicolumn{1}{c|}{ Peluang } \\
\hline Produk berkualitas & Banyak potensi produk yang bisa diimpor \\
\hline Sudah adanya cabang di kota besar di Indonesia & Tumbuhnya ekonomi di kota kota kecil selain ibukota \\
\hline Bisa memberikan harga bersaing jika pembelian dalam kuantiti banyak & Pembelian dalam jumlah banyak bisa menurunkan harga beli \\
\hline Selalu ikut dalam exhibition minimal 2 kali setahun & Pemasaran secara online sedang naik daun \\
\hline Memiliki Chef yang bisa membantu menawarkan produk & Apabila karyawan diberikan pendidikan, bisa menunjukan kinerja lebih baik \\
\hline Sudah memiliki ISO sebagai standar prosedur operasi & Adanya tingkat sertifikasi yang lebih tinggi dari yang sudah ada sekarang \\
\hline Sudah memiliki gudang terpusat yang cukup besar & Perusahaan bisa membuka showroom di setiap cabang \\
\hline \multicolumn{1}{|c|}{ Kelemahan } & \multicolumn{1}{c|}{ Ancaman } \\
\hline Varian produk yang terlalu banyak & Banyaknya muncul produk substitusi yang lebih murah \\
\hline Wilayah distribusi belum nasional & Kompetitor memiliki kantor cabang di lebih banyak kota \\
\hline Harga produk sering di atas kompetitor & Fluktuasi nilai tukar rupiah yang mempengaruhi harga jual \\
\hline Terlalu banyak brand membuat promosi tidak fokus & Trend makanan cepat sekali berubah \\
\hline Tenaga penjual yang belum terlalu menguasai produk secara detail & Adanya kemungkinan karyawan yang bagus akan dibajak perusahaan lain \\
\hline Proses pemberian TOP yang berbelit-belit bagi pelanggan baru & Masih banyak bergantung pada sistem pesanan manual \\
\hline Belum memiliki Gudang pendingan di seluruh Indonesia & Kompetitor memiliki kantor dan gudang yang lebih besar \\
\hline
\end{tabular}

\section{KESIMPULAN DAN SARAN}

\section{Kesimpulan}

a. Setelah dilakukan analisis Internal Factor evaluation dan External Factor Evaluation. Ditemukan bahwa kekuatan utama perusahaan adalah "produk berkualitas", kelemahan utama perusahaan adalah "tenaga penjual yang belum menguasai produk secara detail", peluang utama perusahaan adalah "Banyak potensi produk yang bisa diimpor" dan ancaman utama perusahaan adalah "Kompetitor memiliki kantor cabang di lebih banyak kota".

b. Hasil analisis matriks IE, menunjukan bahwa posisi PT. Prambanan ada di posisi V, dan strategi yang tepat adalah Hold and Maintain Strategy, yaitu penetrasi pasar dan pengembangan produk.

c. Dari Hasil analisis IFE dan EFE, maka timbul 4 strategi yaitu Strategi SO, ST, WO, WT sebagai berikut :

\begin{tabular}{|l|l|}
\hline \multirow{2}{*}{$\begin{array}{l}\text { Strategi } \\
\text { SO }\end{array}$} & $\begin{array}{l}\text { Menawarkan produk berkualitas yang ditawarkan oleh Chef melalui channel } \\
\text { internet }\end{array}$ \\
\cline { 2 - 3 } Strategi & Menggunakan exhibition untuk memperkenalkan produk impor yang baru \\
\hline \multirow{3}{*}{ WO } & $\begin{array}{l}\text { Memberikan pendidikan baik formal maupun informal dan training agar } \\
\text { tenaga penjual lebih menguasai produk }\end{array}$ \\
\cline { 2 - 3 } & $\begin{array}{l}\text { Melakukan promo diskon pembelian dalam jumlah banyak agar harga bisa } \\
\text { kompetitif melawan kompetitor }\end{array}$ \\
\hline \multirow{3}{*}{$\begin{array}{l}\text { Strategi } \\
\text { ST }\end{array}$} & $\begin{array}{l}\text { Memaksimalkan Chef yang ada untuk memberikan ide atau inspirasi pada } \\
\text { pelanggan }\end{array}$ \\
\cline { 2 - 3 } & $\begin{array}{l}\text { Memberikan penawaran diskon untuk pembelian jumlah banyak untuk } \\
\text { produk berkualitas untuk melawan produk substitusi yang lebih murah }\end{array}$ \\
\hline \multirow{3}{*}{ Strategi } & $\begin{array}{l}\text { Melatih tenaga penjual agar menguasai produk secara detail agar dapat } \\
\text { menguasai trend makan yang cepat berubah }\end{array}$ \\
\cline { 2 - 3 } WT & $\begin{array}{l}\text { Membuka titik distribusi di lebih banyak kota agar bisa bersaing dengan } \\
\text { kompetitor }\end{array}$ \\
\hline
\end{tabular}




\section{Saran}

a. Bagi PT. Prambanan Kencana, harus berusaha mengembangkan strategi pemasaran yang baru dari hasil penelitian ini

b. Bagi akademisi atau peneliti selanjutnya diharapkan untuk bisa melakukan penelitian mengenai kinerja keuangan perusahaan, kegiatan operasional perusahaan sehingga penelitian-penelitian tersebut diharapkan dapat membantu pemilik perusahaan untuk meningkatkan penjualan perusahaan.

\section{DAFTAR PUSTAKA}

David, F. R. (2011). Manajemen Strategis Konsep. Jakarta: Salemba Empat.

Kasali, R. (1998). Segmenting, Targeting, and Positioning. Jakarta: Gramedia Pustaka Utama. Ling, L. C. (2006). Journal of American Academy of Business, 296.

yasmin, P. a. (2017). Menperin: Industri Makanan dan Minuman Tumbuh 9,23\%. https://finance.detik.com/industri/d-3985814/menperin-industri-makanan-danminuman-tumbuh-923.

Jagdish N. S., \& Sharma. A. (2005). International E-marketing, opportunities and issues, International Marketing Review.

Kotler, P., \& Armstrong, G. (2008). Prinsip-Prinsip Pemasaran Jilid 1. Jakarta: Erlangga.

Lamb, C., Hair, J., \& McDaniel, C. (2001). Pemasaran Edisi Pertama. Jakarta: Salemba Empat. 